\title{
Cytokines and Extrahepatic Sequelae of Ischemia-Reperfusion Injury to the Liver ${ }^{a}$
}

\author{
DANIEL G. REMICK, LISA M. COLLETTI, ${ }^{b}$ \\ WENDY A. SCALES, ${ }^{b}$ KENNETH R. MCCURRY, ${ }^{b}$ \\ AND DARRELL A. CAMPBELL, JR. ${ }^{b}$ \\ Department of Pathology \\ ${ }^{b}$ Department of Surgery \\ University of Michigan Medical Center \\ Ann Arbor, Michigan 48109
}

\section{INTRODUCTION}

Liver injury is associated with a significantly poor clinical outcome, and patients with end-stage liver disease are at increased risk for the development of adult respiratory distress syndrome. ${ }^{1,2}$ The mediators of this acute lung injury are not known. Recently attention has focused on the role(s) of cytokines in the initiation and propagation of the inflammatory response. Upregulation of cytokines have been found in several diseases, ${ }^{3}$ and a direct cause and effect relationship between the presence of cytokines and organ injury has been suggested. Several investigators have demonstrated that tumor necrosis factor (TNF) has the potential to directly cause damage to multiple organs, including the liver ${ }^{4}$ and the lung. ${ }^{5,6}$ This pulmonary damage may occur in the absence of neutrophils. ${ }^{7}$ Additionally, TNF has been recovered from the lavage fluid of patients with adult respiratory distress syndrome, ${ }^{8}$ and patients at risk for developing nosocomial pneumonia. ${ }^{9}$

We sought to determine the link between acute hepatic injury, the production of TNF, and the development of pulmonary injury. Hepatic injury was induced by ischemia followed by reperfusion, and blood was sequentially sampled and assayed for the presence of TNF. Lung and liver injury was assessed by multiple parameters. The specific role of TNF was investigated by inhibiting TNF with neutralizing antiserum and evaluating the organ injury.

a This work was supported in part by National Institutes of Health Grants GM44918 and DK42455. 


\section{MATERIAL AND METHODS}

\section{Experimental Design}

Male, Sprague-Dawley rats were used for all experiments, as previously described in detail. ${ }^{10,11}$ The animals were heparinized to ensure that thrombosis would not occur during the ischemic period. Partial hepatic ischemia was induced by placing a microaneurism clip on the portal venous and hepatic arterial vessels, occluding the blood flow to the cephalad portion of the liver (see FIGURE 1 for a diagram of the clip placement). For experiments where the blood was sampled sequentially, a catheter was placed in the right external jugular vein and positioned just above the dome of the liver. Blood was removed from the indwelling catheter and replaced with an equal volume of lactated Ringer's solution.

\section{TNF Assay}

TNF was measured by the highly sensitive WEHI 164 subclone 13 cell line. These cells are exquisitely sensitive to the cytolytic action of TNF, detecting as little as 2 $\mathrm{pg} / \mathrm{ml} .^{12,13}$ For these studies, the samples were measured in the bioassay, so that all of the data presented represent biologically active TNF, rather than only immunologically active TNF as would be measured in an ELISA. To measure the TNF, the heparinized plasma is diluted 1:10 with RPMI 1640 (Gibco, Detroit, MI) and then serially diluted in a 96-well plate. The WEHI cells are resuspended in RPMI 1640 media with additives, including $0.5 \mu \mathrm{g} / \mathrm{ml}$ actinomycin D (Calbiochem, LaJolla, CA). After an overnight incubation, cell viability is assessed with MTT-tetrazolium. ${ }^{14}$

\section{IL-6 Assay}

IL-6 was measured by its ability to induce the proliferation of B9 cells. ${ }^{15}$ Briefly, cells are grown in serial dilutions of the samples. After 3 days, cell viability was assessed by MTT-tetrazolium, as described for the TNF assay. Again, the IL-6 data represent biologically active material, rather than merely immunologically reactive.

\section{Anti-TNF Antiserum}

Polyclonal, rabbit anti-murine TNF antiserum was prepared by immunizing rabbits with recombinant murine TNF. This antiserum neutralizes both recombinant and natural murine TNF, as determined in a cell killing assay. It crossreacts with rat TNF and has no crossreactivity with interleukin 1 . This antiserum is diluted $1: 1$ with RPMI 1640 and $2 \mathrm{ml}$ was injected intravenously immediately before the onset of ischemia. For controls, serum from non-immunized rabbits was given in the similar protocol. The control serum had no TNF neutralizing ability. 


\section{Assessment of Pulmonary Injury}

Injury to the pulmonary vasculature was measured by two independent methods. For the first, the capillary permeability is measured by the loss of ${ }^{125} \mathrm{I}$-albumin from the vasculature. For this method, ${ }^{125} \mathrm{I}$-labeled albumin is injected intravenously, and $3 \mathrm{~h}$ later $1 \mathrm{ml}$ of blood is collected. The lungs are flushed with normal saline to remove blood remaining within the vasculature. The radioactivity in both the lungs and the blood was measured in a gamma counter (Beckman Instruments, Fullerton, CA). The mean permeability index was calculated by dividing the $\mathrm{cpm} / \mathrm{g}$ of lung tissue by the $\mathrm{cpm} / \mathrm{g}$ of the blood. This is representative of leakage of the radiolabeled albumin from the blood into the lung. Lung injury was also assessed by histologic examination, as described below.

\section{Assessment of Liver Injury}

Serum SGPT was used as a marker of liver injury. Serum was prepared from blood drawn at the time of sacrifice and was analyzed by routine methods in clinical chemistry from the Department of Pathology at the University of Michigan Hospitals.

\section{Histology}

Sections of lung and liver were prepared from animals. Tissues were fixed in buffered formalin, embedded in paraffin, and hematoxylin-eosin-stained sections prepared. All tissues were examined by a pathologist in a blinded manner and evaluated for injury.

\section{RESULTS}

\section{Cytokine Production}

One of the first experiments was to measure the production of cytokines in the plasma of rats after ischemia-reperfusion (I-R). As shown in Figure 2, 90 min of partial ischemia in heparinized rats induces clearly detectable, biologically active TNF. Several of these samples were also analyzed in the presence of anti-TNF antiserum, which completely inhibited the biological activity present within the plasma, helping to confirm that the material in the samples was, indeed, TNF. We have also prepared tissue homogenates of the ischemic and nonischemic portions of the liver, and have shown that TNF is present within these tissue homogenates during the reperfusion period. ${ }^{16}$ In other experiments, we have demonstrated that $2 \mathrm{~h}$ of partial ischemia in nonheparinized rats will also induce production of TNF in the blood, as well as IL-6. ${ }^{17}$

\section{Hepatic Injury}

The liver develops severe injury during the reperfusion period. FIGURE 3 shows the hepatic histology after $l$ (A) and 24 (B) h of reperfusion injury. Although there is a substantial increase in the hepatic enzymes after $l \mathrm{~h}$, the hepatic architecture remains 


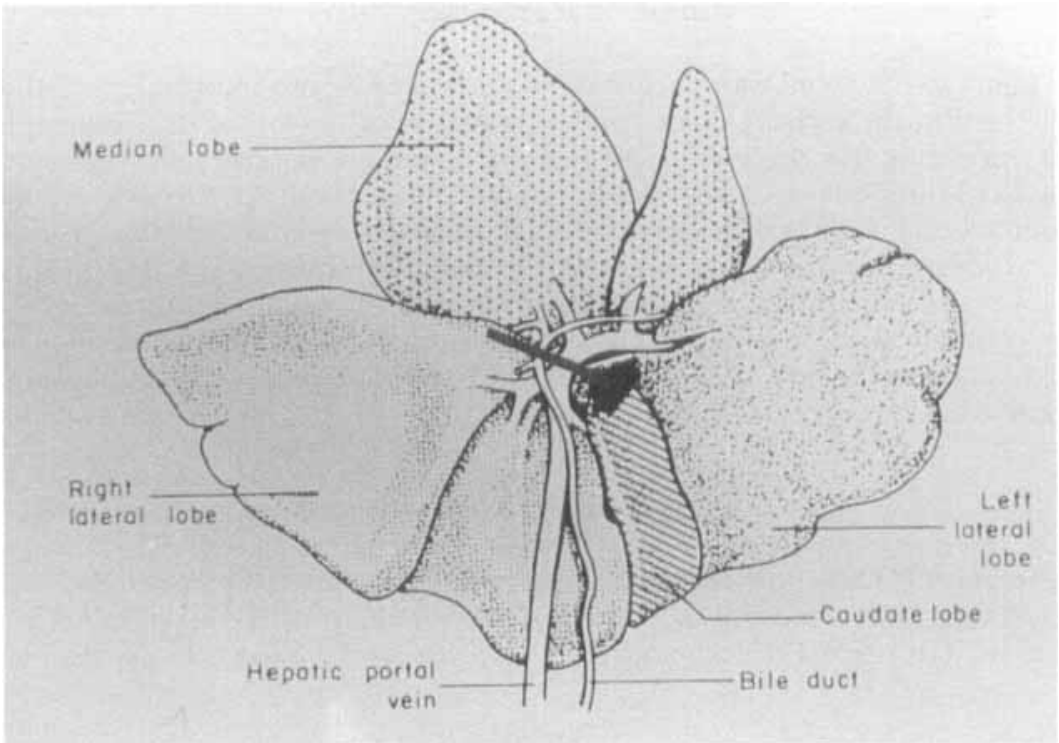

FIGURE 1. Placement of clip for vascular occlusion. The microaneurism clip is placed across the vasculature as indicated by the black bar. This completely occludes both the venous and arterial blood supply to the cephalad three lobes, while leaving the caudal three lobes vasculature intact. (Adapted from Colletti et al. ${ }^{10}$ )

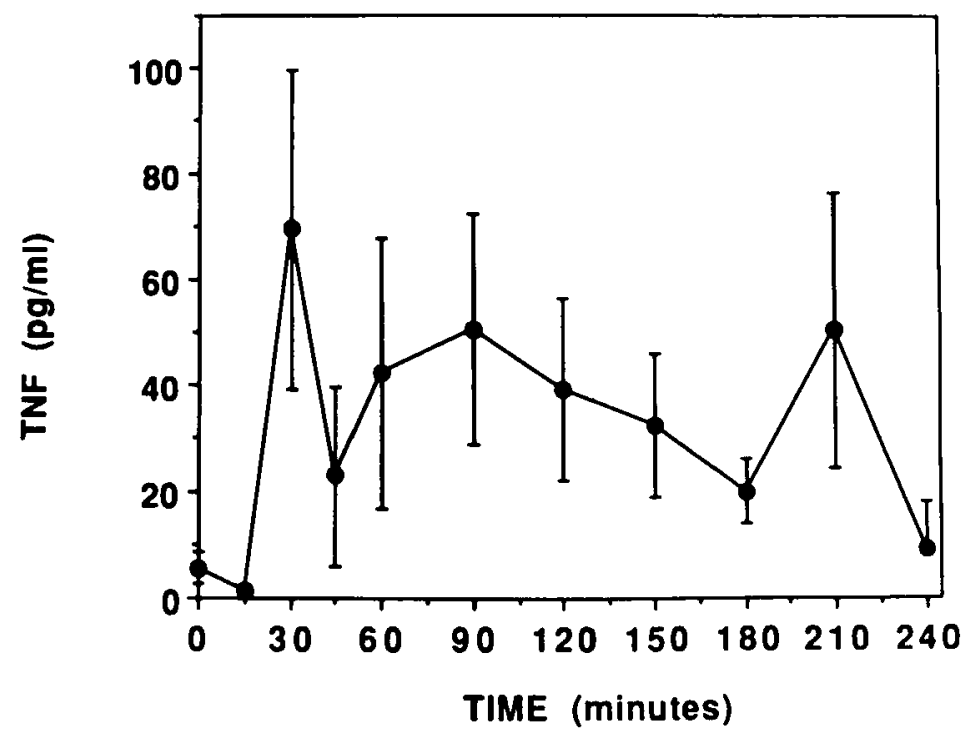

FIGURE 2. TNF production after hepatic ischemia-reperfusion. Reperfusion began at time 0 , and the presence of TNF was measured in the plasma. Each point is the mean \pm SEM for 8 to 14 rats. (From Colletti et al. ${ }^{11}$ Reprinted with permission.) 


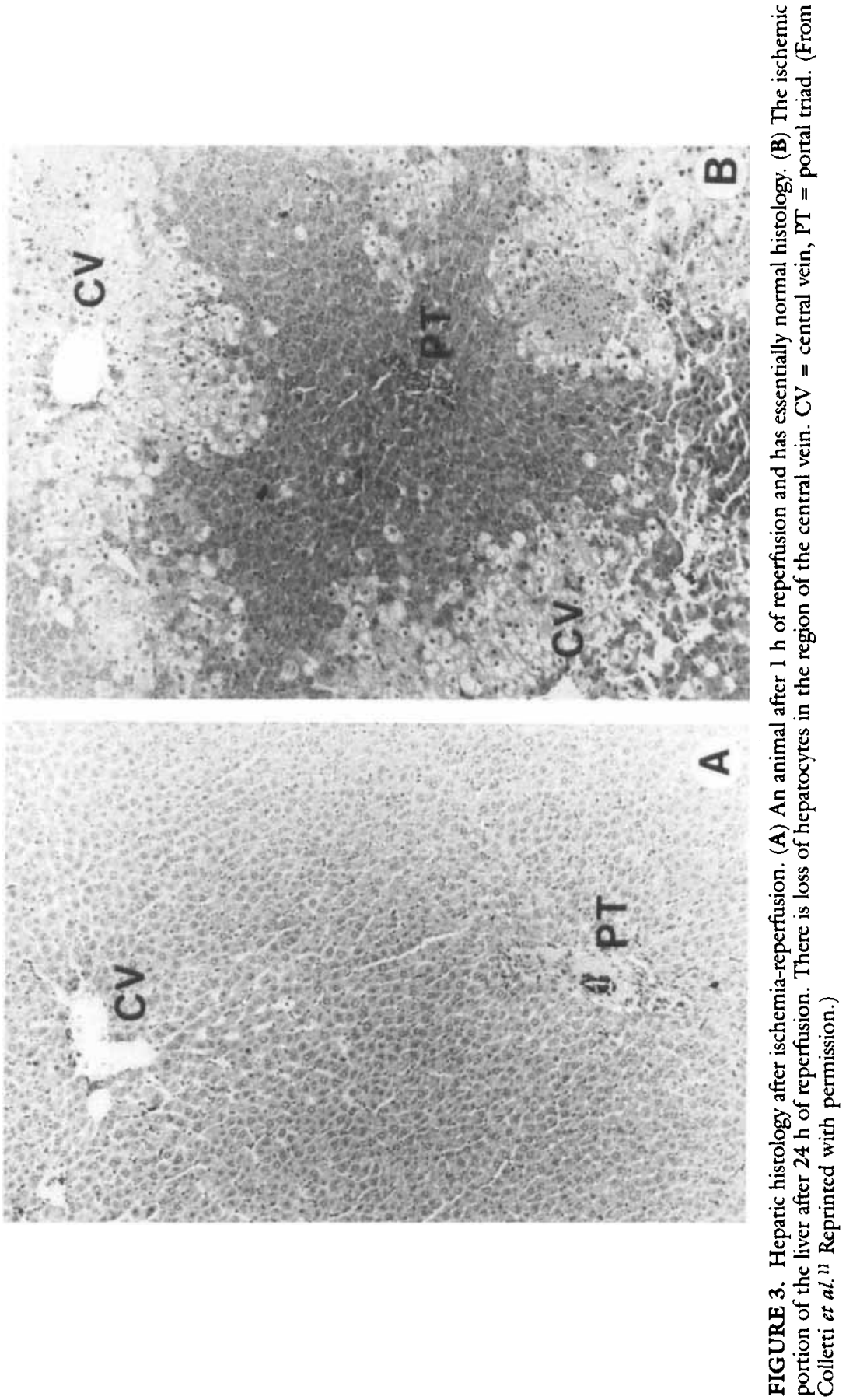


intact at the light microscopic level. Significantly, there is no neutrophil influx into the liver at this time. Morphometric assessment of the neutrophil infiltration has demonstrated that these inflammatory cells are not recruited to the liver until after approximately $6 \mathrm{~h}$ of reperfusion (data not shown). By $24 \mathrm{~h}$ there is severe hepatic damage that can be readily appreciated at the light microscopic level (FIG. 3, B). The hepatic parenchyma in the region of the central vein shows the most severe disruption. This is the typical pattern of injury induced by a low blood flow situation, since these cells are the most distant from the nutrients and oxygen arriving from the vasculature of the portal triad. The hepatocytes have undergone severe changes, and the cells may be characterized as having vacuolated, swollen cytoplasm, such that the sinusoidal architecture is disrupted. In focal areas the injury has progressed so that the cells have collapsed with resulting eosinophilic cytoplasm. The nuclei in both areas of necrotic liver demonstrate pyknosis with shrunken, darkly staining nuclei. In many of these necrotic areas there is a brisk infiltrate of neutrophils at the 24-h time point.

\section{Inbibition of Liver Injury with Anti-TNF Antibodies}

We now have an association of upregulation of circulating levels of TNF, and increased tissue levels of TNF after hepatic ischemia-reperfusion. However, this is an association, and does not imply a cause and effect relationship. ${ }^{18}$ To delineate the relationship between the presence of TNF, and the development of hepatic injury, we treated rats with anti-TNF antibodies and then induced ischemia-reperfusion. Blood was obtained after 3 and 24 h of reperfusion, and analyzed for serum glutamic pyruvic transaminase (SGPT, now routinely called alanine aminotransferase, or ALT). FIGURE 4 shows the results of the antiserum inhibition. In the sham-operated animals, SGPT levels are at normal levels. However, within $3 \mathrm{~h}$ of reperfusion they are elevated to nearly 3,000 IU/1 (FIG. 4, A), and by $24 \mathrm{~h}$ SGPT is over 6,000 IU/l (FIG. 4, B). To control for any nonspecific effects that may have been induced by the rabbit serum, a group of rats was treated with control serum that has no TNF-neutralizing capacity. These control serum-treated rats had the same SGPT levels as animals subjected to ischemia-reperfusion without any additional treatments. However, pretreatment with anti-TNF antiserum blocked the liver injury at both the 3 and $24 \mathrm{~h}$ time point, as measured by a significant reduction in the SGPT levels. These data strongly implicate TNF as a mediator of the liver injury observed after ischemia-reperfusion.

\section{Pulmonary Injury after Hepatic Iscbemia-Reperfusion}

Other organs frequently show dysfunction after the liver has suffered injury. Since endogenously produced TNF has been implicated as a mediator of lung injury, ${ }^{19,20}$ and we have evidence both of TNF production as well as its role in liver injury we sought to determine if there is lung injury, and if TNF plays a role. The first set of experiments was designed to precisely delineate the kinetics of pulmonary injury after hepatic ischemia-reperfusion. Capillary permeability was measured by the leakage of radioactive albumin from the vasculature into the lungs, a technique that has been widely used to document acute lung injury in experimental models. ${ }^{21-25}$ Figure 5 shows the kinetics of the increase in capillary permeability following I-R. An increase is observed within $3 \mathrm{~h}$, which peaks between 9 to $12 \mathrm{~h}$. The injury then resolves, and 

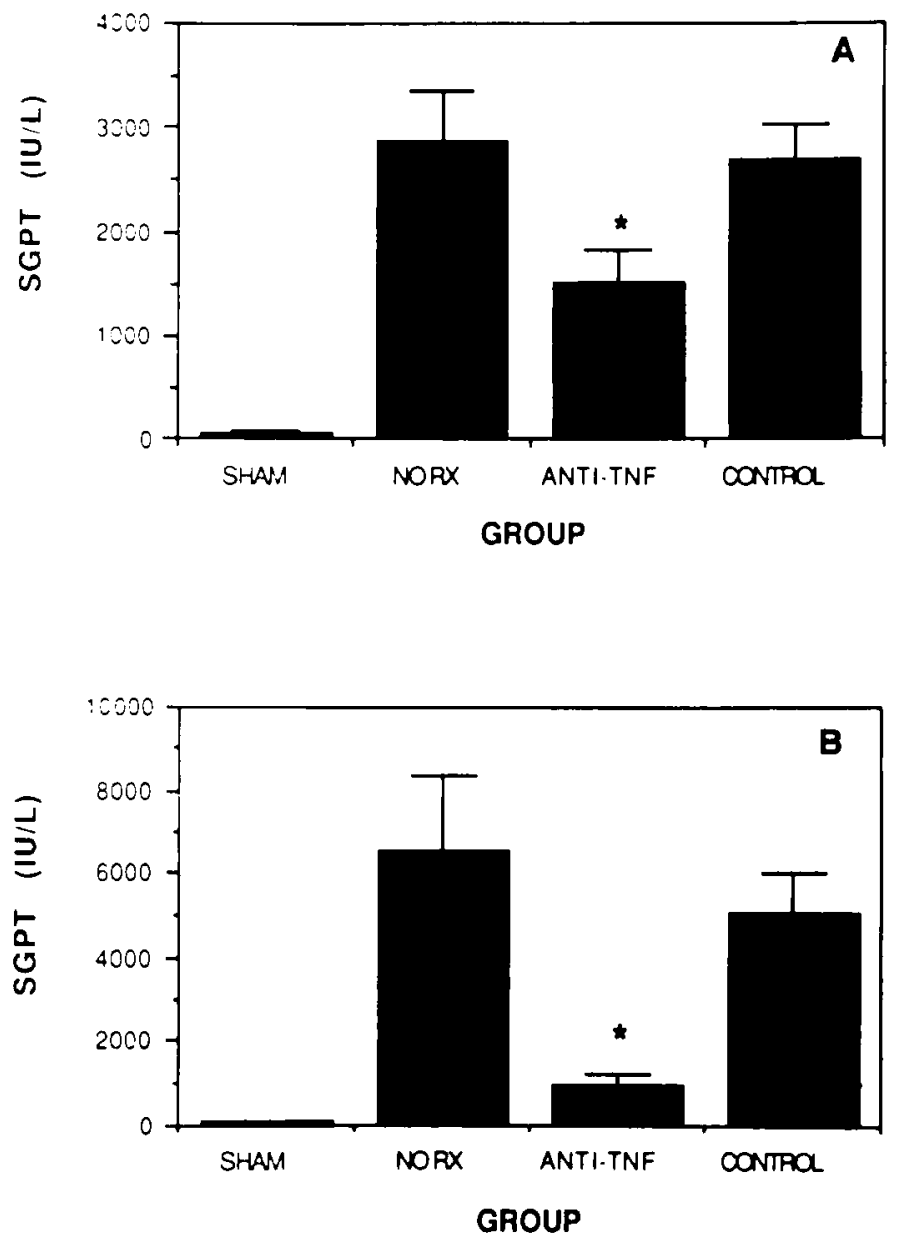

FIGURE 4. Anti-TNF inhibition of liver injury. Rats were subjected to sham operation (sham), ischemia-reperfusion injury with no other interventions (NO RX), or were pretreated with antiTNF antiserum or control rabbit serum. SGPT enzyme levels after $3 \mathrm{~h}$ of reperfusion (A) and after $24 \mathrm{~h}(\mathrm{~B})$. At either time point, there is significant protection as determined by a reduction in the hepatic enzyme SGPT. Each value is the mean \pm SEM. ${ }^{*} p<0.05$ compared to control serum. (From Colletti et al." Reprinted with permission).

capillary permeability returns to baseline within 15 to $18 \mathrm{~h}$. This injury is observed in the heparinized, $90-\mathrm{min}$ ischemia model, and similar results were obtained in the 2-h, nonheparinized model. ${ }^{17}$

Again, the documentation of the lung injury is only associated with an increase of TNF. To clearly establish the relationship, we pretreated animals with the anti-TNF antiserum as described previously. Lung injury was assessed after $12 \mathrm{~h}$ of reperfusion, near the peak of lung injury. FIGURE 6 shows the results of these studies and demonstrates that the anti-TNF antiserum afforded significant protection. In fact, inhibition 

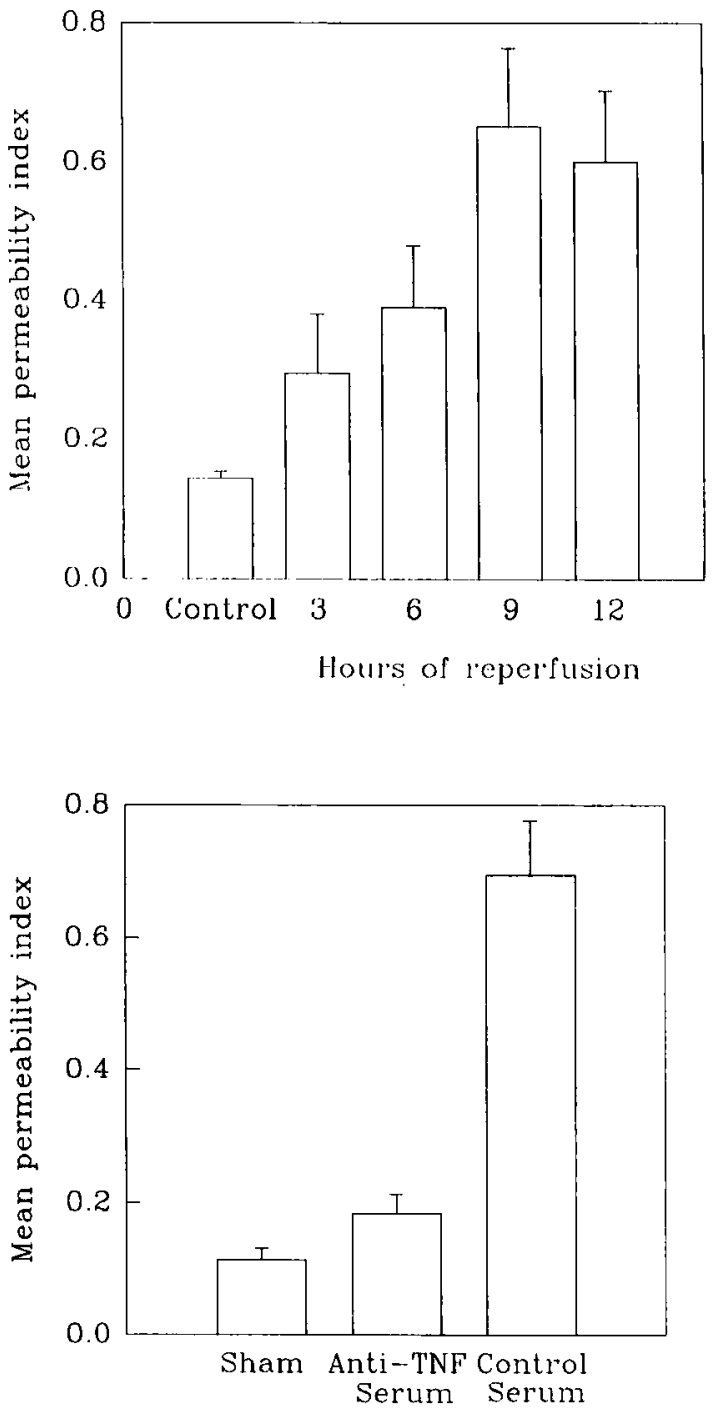

FIGURE 5. Kinetics of increased pulmonary capillary permeability after hepatic ischemiareperfusion. The mean permeability index peaked after 9 to $12 \mathrm{~h}$ of reperfusion. Additional experiments showed a return to baseline by $15 \mathrm{~h}$. Each value is the mean $\pm S E M$.

FIGURE 6. Anti-TNF antiserum prevents pulmonary injury. Rats were pretreated with anti-TNF antiserum and pulmonary capillary permeability was assessed after 12 h. Anti-TNF antiserum reduced the mean permeability index to the same level as the sham-operated animals, and this reduction is significantly decreased compared to the control serum-treated animals. Each value is the mean \pm SEM. (Adapted from Colletti $e t a l .{ }^{10}$ )

FIGURE 7. Lung histology after anti-TNF treatment. Rats were subjected to hepatic ischemia and the pulmonary changes evaluated $12 \mathrm{~h}$ later. (a) Sham-operated rats show normal histology. (b) Rats after I-R. There is focal intraalveolar hemorrhage and edema fluid. (c) A similar histologic picture of pulmonary injury in rats treated with control serum. (d) Virtually complete protection from the lung injury is observed in rats treated with anti-TNF serum. All pictures same magnification. (From Colletti et al. ${ }^{11}$ Reprinted with permission.) 


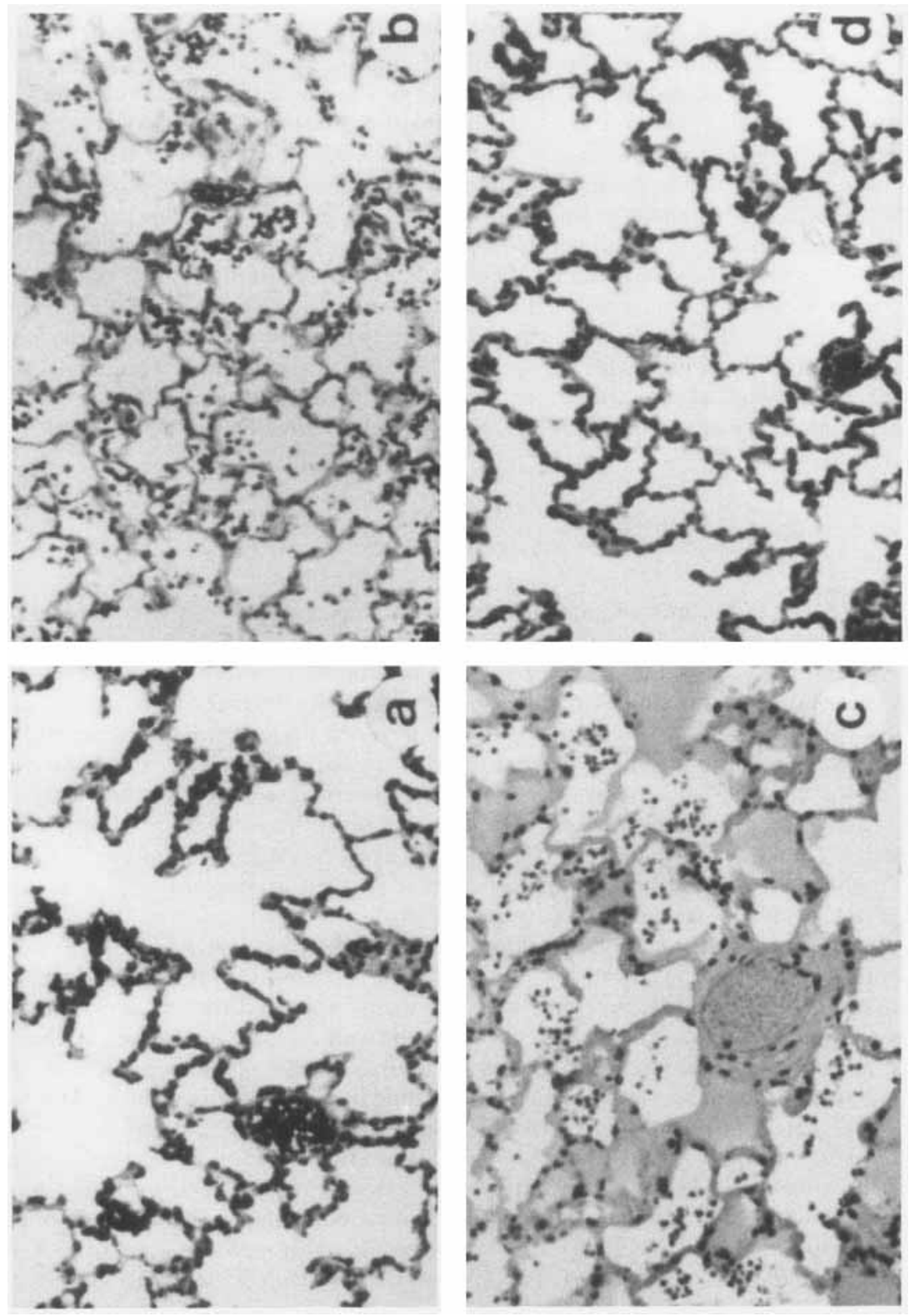


of TNF resulted in capillary permeability that was nearly identical to sham-operated animals.

We also evaluated lung injury by microscopic examination of the lungs in groups of rats separate from those used for the permeability index. This is an independent method of determining lung injury, and the findings would corroborate the ${ }^{125} \mathrm{I}$ labeled albumin leak shown in Figures 5 and 6. Photomicrographs of the injury are shown in Figure 7. In Figure 7 (a), normal lung histology is observed in shamoperated rats. The alveoli are clear, with no evidence of hemorrhage or edema fluid. In contrast, after $12 \mathrm{~h}$ of reperfusion, many of the alveoli contain extravasated red blood cells and wisps of protein-containing fluid (FIG. 7, b). This histologic picture confirms the permeability data, since the proteins leak from the vascular space into the alveolus where they will remain until cleared. The histology also demonstrates that the increase in radioactivity in the lung is not just due to proteolytic cleavage of the ${ }^{125} \mathrm{I}$. When rats are treated with control rabbit serum, there is no resolution of the lung injury (FIG. $7, \mathrm{c}$ ), and the edema fluid within the alveoli appears to be even more prominent. $\mathrm{Nu}$ merous red blood cells are also present in virtually all of the alveoli. Blockade of TNF with an anti-TNF antiserum, however, results in an essentially normal histologic picture (FIG. 7, d).

\section{DISCUSSION}

Our data clearly demonstrate that ischemia and reperfusion of the liver induces the production of TNF, and that this newly synthesized TNF is responsible for a portion of the ensuing liver and lung injury. ${ }^{10,11}$ The production of cytokines in response to $\mathrm{I}-\mathrm{R}$ was an unusual finding. While there are several mediators that the liver could produce, the cytokines have come to the forefront in our understanding of multiple aspects of inflammation. Cells of the macrophage/monocyte lineage are the major producers of cytokines and the liver has enormous potential to produce cytokines since the Kupffer cells represent one of the largest reservoirs of resident macrophages in the body. If cytokines are made, is TNF the most likely to cause lung injury? TNF has been shown to induce lung injury, whether it is given exogenously, ${ }^{26,27}$ thus, our data should not be viewed with surprise.

One hypothesis for the observed lung injury is that the liver fails to perform its normal function; specifically it does not clear toxic substances from the blood stream. As a result of this inadequate clearance, these toxins will travel to the next organ and cause injury. An alternative hypothesis is that the liver actually synthesizes molecules that then move to the lung to induce organ injury. Because of its anatomic location, substances produced by the liver will reach the lung in greatest concentration. The liver is also an ideal organ to produce cytokines, since one of its principal functions in the body is the synthesis of proteins. Any protein produced and exported to the blood stream by the liver would be transmitted directly to the lung. This is a different function of the liver, where it actively participates in tissue injury by the synthesis of potentially toxic substances. However, it is possible that although the liver made TNF, it never intended it to be released. The TNF may be present on the surface of the cells to induce synthesis of hepatic acute phase proteins by the neighboring hepatocytes. ${ }^{28,29}$ To differentiate between the possibility that the TNF was never meant for export or it was only to remain on the surface of the cells, Western blot analysis must be performed. Surface-bound TNF is $26 \mathrm{kD}$, while the secreted form is $17 \mathrm{kD}$. If 
Western blot analysis of liver samples shows the $26 \mathrm{kD}$ form of the protein, then TNF was probably released as the cells in the liver were dying. Studies are underway to address this question directly.

There have been additional reports that have helped to substantiate our original hypothesis that TNF is the mediator of organ injury after hepatic ischemia-reperfusion. The classic inducers of cytokine synthesis are inflammatory stimuli, such as lipopolysaccharide ${ }^{30}$ or immune complexes. ${ }^{31}$ Our model of partial hepatic ischemia prevents mesenteric congestion and translocation of bacteria into the blood. Using a sensitive Limulus lysate assay, endotoxin could not be detected in the blood, which rules out the possibility that a small amount of endotoxin is responsible for the induction of TNF. Additionally, a recent report has indicated that hemorrhagic shock by itself will induce circulating levels of TNF. ${ }^{32}$

There have been other reports that point towards the involvement of TNF in the pathogenesis of the liver injury. Lim et al. have published that a prostaglandin E analog will provide hepatoprotection during $\mathrm{I}-\mathrm{R},{ }^{33}$ and we have previously demonstrated that PGE will block TNF protection at the level of transcription. ${ }^{34}$ Recent reports have also shown that the immunosuppressive agent cyclosporin $A$ (CsA) and FK $506^{35,36}$ will protect the liver from ischemia-reperfusion-induced damage. CsA has been shown to decrease TNF production in both humans ${ }^{37}$ and rodents. ${ }^{38,39} \mathrm{Sakr}$ et al. specifically demonstrated that treatment with FK 506 provided significant protection and that this was associated with a decrease in the levels of TNF. 40

Taken collectively, the published literature and our data strongly support the hypothesis that TNF is one of the principal mediators of organ injury observed after ischemia-reperfusion. While TNF is important, it is probably not the only mediator. Neutrophils may contribute to part of the liver injury, ${ }^{41}$ especially in the later stages. ${ }^{42}$ Generation of reactive oxygen species has also been shown after ischemiareperfusion and these toxic metabolites may also play a significant role. ${ }^{43-45}$ All of these events are probably interrelated and the final outcome is most likely due to multiple interactions. The challenge for the future is to carefully dissect the relative contribution of each of these events to arrive at specific, targeted therapy to effectively block both the liver and the lung injury.

\section{REFERENCES}

1. Matuschak, G. M., J. E. Rinaldo, M. R. Pinsky, J. S. Gavaler \& D. H. Van Thiel. 1987. Effect of end-stage liver failure on the incidence and resolution of the adult respiratory distress syndrome. J. Crit. Care 2: 162-173.

2. Matuschak, G. M. \& J. E. Runaldo. 1988. Organ interactions in the adult respiratory distress syndrome during sepsis. Chest 94: 400-406.

3. Cytokines in Health and Disease. 1992. S. L. Kunkel \& D. G. Remick, Eds. Marcel Dekker, Inc. New York.

4. Talmadge, J. E., O. Bowersox, H. Trubble, S. H. Lee, H. M. Shepard \& D. Liggitt 1987. Toxicity of tumor necrosis factor is synergistic with gamma-interferon and can be reduced with cyclooxygenase inhibitors. Am. J. Pathol. 128: 410-425.

5. Tracey, K. J., Y. Fong, D. G. Hesse, K. R Manogue, A. T. Lee, G. C. Kuo, S. F. LOWRY \& A. CERAMI. 1987. Anti-cachectin/TNF monoclonal antibodies prevent septic shock during lethal bacteraemia. Nature 330: 662-664.

6. Remick, D. G. \& S. L. Kunkel. 1993. Pathophysiologic alterations induced by tumor necrosis factor. In International Review of Experimental Pathology Cytokine-induced Pathology. B. Ryffell, Ed:7-26. Academic Press. New York. 
7. Horvath, C. J., T. J. Ferro, G. Jesmok \& A. B. Malik. 1988. Recombinant tumor necrosis factor increase pulmonary vascular permeability independent of neutrophils. Proc. Natl. Acad. Sci. USA 85: 9219-9223.

8. Millar, A. B., N. M. Foley, M. Singer, N. M. Johnson, A. Meager \& G. A. Rook. 1989. Tumour necrosis factor in bronchopulmonary secretions of patients with adult respiratory distress syndrome. Lancet 2: 712-714.

9. Rodriguez, J. L., C. G. Miller, W. L. Garner, G. O. Till, P. Guerrero, N. P. Moore, M. Corrudore, D. P. Normolle, D. J. Smith \& D. G. Remick. 1993. Correlation of the local and systemic cytokine response with clinical outcome following thermal injury. J. Trauma 34: 684-694 (discussion 694-695.)

10. Colletti, L. M., G. D. Burtch, D. G. Remick, S. L. Kunkel, R. M. Strieter, K. $S$. Guice, K. T. OLdham \& D.-A. CAmpBell, JR. 1990. The production of tumor necrosis factor alpha and the development of a pulmonary capillary injury following hepatic ischemia/reperfusion. Transplantation 49: 268-272.

11. Colletti, L. M., D. G. Remick, G. D. Burtch, S. L. Kunkel, R. M. Strieter \& D. A. CAMpBelL, JR. 1990. Role of tumor necrosis factor-alpha in the pathophysiologic alterations after hepatic ischemia/reperfusion injury in the rat. J. Clin. Invest. 85: 1939-1943.

12. Eskandaru, M. K., D. T. Nguyen, S. L. Kunkel \& D. G. Remick. 1990. WEHI 164 subclone 13 assay for TNF: sensitivity, specificity and reliability. Immun. Invest. 19: 69-79.

13. Espevik, T. \& J. Nissen MeYer. 1986. A highly sensitive cell line, WEHI 164 clone 13, for measuring cytotoxic factor/tumor necrosis factor from human monocytes. J. Immunol. Methods 95: 99-105.

14. Mosmann, T. 1983. Rapid colorimetric assay for cellular growth and survival: Application to proliferation and cytotoxicity assays. J. Immunol. Methods 65: 55-63.

15. Aarden, L. A., E. R De Groot, O. L. SchaAp \& P. M. Lansdorp. 1987. Production of hybridoma growth factor by human monocytes. Eur. J. Immunol. 17: 1411-1416.

16. Howatt, M. E., D. G. Remick, W. E. Scales \& D. A. Campbell, JR. 1992. Tissue associated TNF following hepatic ischemia. FASEB J. 6: abstract.

17. McCurry, K. R, D. A. Campbell JR., J. S. Warren, W. E. Scales \& D. G. Remick. 1994. TNF, IL-6 and the acute phase response following hepatic ischemia reperfusion. J. Surg. Res. 54: 49-54.

18. REMICK, D. G. 1981. Significance of in vivo detection of tumor necrosis factor [editorial; comment]. Lab. Invest. 65: 259-261.

19. Stephens, K. E., A. Ishizaka, J. W. Larrick \& T. A. Raffin. 1988. Tumor necrosis factor causes increased pulmonary permeability and edema. Comparison to septic acute lung injury. Am. Rev. Respir. Dis. 137: 1364-1370.

20. Lilly, C. M., J. S. Sandhu, A. Ishizaka, H. Harada, M. Yonemaru, J. W. Larrick, T. X. Shi, P. T. O'Hanley \& T. A. Raffin. 1989. Pentoxifylline prevents tumor necrosis factor-induced lung injury. Am. Rev. Respir. Dis. 139: 1361-1368.

21. Johnson, K. J., B. S. Wilson, G. O. TIll \& P. A. WARD. 1984. Acute lung injury in rat caused by immunoglobulin $A$ immune complexes. J. Clin. Invest. 74: 358-369.

22. Johnson, K. J., P. A. WARD, R. G. Kunkel \& B. S. WuLson. 1986. Mediation of IgA induced lung injury in the rat. Role of macrophages and reactive oxygen products. Lab. Invest. 54: 499-506.

23. Till, G. O., M. L. Morganroth, R. Kunkel \& P. A. Ward. 1987. Activation of C5 by cobra venom factor is required in neutrophil-mediated lung injury in the rat. Am. J. Pathol. 129: 44-53.

24. Seekamp, A., J. S. Warren, D. G. Remick, G. O. Till \& P. A. Ward. 1993. Requirements for tumor necrosis factor-alpha and interleukin-I in limb ischemia/reperfusion injury and associated lung injury. Am. J. Pathol. 143: 453-463.

25. Remick, D. G., R. G. KunkeL, J. W. LARPuck \& S. L. Kunkel. 1987. Acute in vivo effects of human recombinant tumor necrosis factor. Lab. Invest. 56: 583-590.

26. Remick, D. G. \& S. L. Kunkel. 1993. Pathophysiologic alterations induced by tumor necrosis factor. Int. Rev. Exp. Pathol. 34: (Pt B):7-25.

27. Tracey, K. J., B. Beutler, S. F. Lowry, J. Merryweather, S. Wolpe, I. W. Milsark, 
R J. Hariri, T. J. Fahey, A. Zentella, J. D. Albert, G. T. Shires \& A. Cerami. 1986. Shock and tissue injury induced by recombinant human cachectin. Science 234: 470-474.

28. Ganapathi, M. K., D. Schultz, A. Mackiewicz, D. Samols, S. I. Hu, A. Brabenec, S. S. MacintYre \& I. Kushner. 1988. Heterogeneous nature of the acute phase response. Differential regulation of human serum amyloid $\mathrm{A}, \mathrm{C}$-reactive protein, and other acute phase proteins by cytokines in Hep 3B cells. J. Immunol. 141: 564-569.

29. Mortensen, R. F., J. Shapiro, B. F. Lin, S. Douches \& R. Neta. 1988. Interaction of recombinant IL-1 and recombinant tumor necrosis factor in the induction of mouse acute phase proteins. J. Immunol. 140: 2260-2266.

30. Deforge, L. E., J. S. Kenney, M. L. Jones, J. S. Warren \& D. G. Remick. 1992. Biphasic production of IL-8 in lipopolysaccharide (LPS)-stimulated human whole blood. Separation of LPS- and cytokine-stimulated components using anti-tumor necrosis factor and anti-IL-1 antibodies. J. Immunol. 148: 2133-2141.

31. Vissers, M. C., J. C. Fantone, R Wiggins \& S. L. Kunkel. 1989. Glomerular basement membrane-containing immune complexes stimulate tumor necrosis factor and interleukin-1 production by human monocytes. Am. J. Pathol. 134: 1-6.

32. Ayala, A., P. Wang, Z. F. Ba, M. M. Perrin, W. Ertel \& I. H. Chaudry. 1991. Differential alterations in plasma IL-6 and TNF levels after trauma and hemorrhage. Am. J. Physiol. 260: Rl67-RI7l.

33. Lim, S. P., F. J. Andrews, C. Chrustophi \& P. E. O'Brien. 1992. Misoprostol hepatoprotection against ischemia-reperfusion-induced liver injury in the rat. Dig. Dis. Sci. 37: 1275-1281.

34. Kunkel, S. L., M. Spengler, M. A. May, R. Spengler, J. Larrick \& D. Remick. 1988. Prostaglandin E2 regulates macrophage-derived tumor necrosis factor gene expression. J. Biol. Chem. 263: 5380-5384.

35. Suzuki, S., L. H. Toledo-Pereyra, F. J. Rodriguez \& D. Cejalvo. 1993. Neutrophil infiltration as an important factor in liver ischemia and reperfusion injury. Modulating effects of FK506 and cyclosporine. Transplantation 55: 1265-1272

36. Sakr, M. F., T. I. Hassanein, G. M. Zetti \& D. H. Van Thiel. 1990. FK 506 ameliorates the hepatic injury associated with ischemia. Life Sci. 47:687-691.

37. Espevik, T., I. S. Figari, M. R Shalaby, G. A. Lackides, G. D. Lewis, H. M. Shepard \& M. A. Palladino. 1987. Inhibition of cytokine production by cyclosporin $A$ and transforming growth factor beta. J. Exp. Med. 166: 571-576.

38. Remick, D. G., D. T. Nguyen, M. K. Eskandari, R. M. Strieter \& S. L. Kunkel. 1989. Cyclosporine A inhibits TNF production without decreasing TNF mRNA levels. Biochem. Biophys. Res. Commun. 161: 551-555.

39. Nguyen, D. T., M. K. Eskandaru, L. E. DeForge, C. L. Raiford, R M. Strieter, S. L. Kunkel \& D. G. Remick. 1990. Cyclosporin a modulation of tumor necrosis factor gene expression and effects in vitro and in vivo. J. Immunol. 144: 3822-3828.

40. Sakr, M. F., C. J. McClain, J. S. Gavaler, G. M. Zetti, T E. Starzl \& D. H. Van THIEL. 1993. FK 506 pre-treatment is associated with reduced levels of tumor necrosis factor and interleukin 6 following hepatic ischemia/reperfusion. J. Hepatol. 17: 301-307.

41. Langdale, L. A., L. C. Flaherty, H. D. Liggitt, J. M. Harlan, C. L. Ruce \& R. K. WINN. 1993. Neutrophils contribute to hepatic ischemia-reperfusion injury by a CD18independent mechanism. J. Leukoc. Biol. 53: 511-517.

42. JAESCHKe, H., A. FARHOOD \& C. W. SMITH. 1990. Neutrophils contribute to ischemia/reperfusion injury in rat liver in vivo. FASEB J. 4: 3355-3359.

43. Gonzalez-Fiecha, B., J. C. Cutrin \& A. Boveris. 1993. Time course and mechanism of oxidative stress and tissue damage in rat liver subjected to in vivo ischemia-reperfusion. J. Clin. Invest. 91: 456-464.

44. Jaeschke, H., A. P. Bautista, Z. Spolarics \& J. J. SpITZER. 1991. Superoxide generation by Kupfer cells and priming of neutrophils during reperfusion after hepatic ischemia. Free Radic. Res. Commun. 15: 277-284.

45. Jaeschke, H., A. P. Bautista, Z. Spolarics \& J. J. Spitzer. 1992. Superoxide generation by neutrophils and Kupffer cells during in vivo reperfusion after hepatic ischemia in rats. J. Leukoc. Biol. 52: 377-382. 